\title{
3 Aspectuality as a Complex, Semantic, Universal Category. Theoretical and Methodological Foundations
}

\subsection{Introductory remarks}

Speakers have a basic set of cognitive and communicative skills and they have the biologically based, socially learned and further developed ability ${ }^{1}$ to connect content with expressions and to use them for very diverse communication purposes: language. The expression ${ }^{2}$ of a meaning, of a function, can be served by various means, which are structured according to different organisational principles. The strategies that speakers have developed in their individual languages for producing this combination of content and expressions, and which they choose in a concrete communicative context, display a rich diversity.

Yet the results of many typological investigations carried out in recent years ${ }^{3}$ have made clear the existence of crosslinguistic constants, ${ }^{4}$ especially when it comes to identifying certain very general linguistic functions as universally-conceived content categories.

However, asserting the possibility of identifying crosslinguistic - i.e., universal in a non-absolute sense - content categories does not mean that speakers only need to transfer universal mentalese into sequences of their language, because the efforts that such a language of the mind would have to exert would be

1 On so-called "social cognition" see Tomasello (1999); see also Ferretti (2006) and De Mauro (2009), in general, on the relationship that connects languages and society with human "naturalness": "[. . . even those who tenaciously supported the idea of biological uniqueness, if not human uniqueness then certainly the uniqueness of human linguistic abilities, have in recent years come to radically rethink this idea of uniqueness, of language as uniquely human, and to admit what others have been thinking for some time now, namely that there is a continuity between the drive of other living species to communicate and the emergence of the ability of humans to use languages and language. This emergence and life consequent to this emergence of linguistic abilities are all wrapped up, so to speak, in social conditioning." (De Mauro 2009, 7f., orig. It.).

2 Of course, humans also have an articulatory-auditory apparatus specialised for speech production and reception.

3 See especially the now classic contributions by Bybee (1985), Bybee/Perkins/Pagliuca (1994) and Dahl (1985 and 2000), but also the more recent works in Song (2011), particularly those by van der Auwera/Gast, Bickel, Cristofaro, de Haan, Moravcsik and Stassen.

4 Dahl (1985) speaks in this context of "crosslinguistic categories".

Ә Open Access. (C) 2019 Sarah Dessì Schmid, published by De Gruyter. (cc) BY-NC-ND This work is licensed under a Creative Commons Attribution-NonCommercial-NoDerivatives 4.0 International License.

https://doi.org/10.1515/9783110562088-004 
enormous. ${ }^{5}$ There are indeed several arguments claiming that the historical form of each of our languages influences our respective Weltansicht ('world view'; see Humboldt 1903-1936, VI/1, 22-23), our way of structuring the world. On the one hand, this shows how problematic absolute forms of universalism are, ${ }^{6}$ but, on the other hand, it certainly does not mean that we should indulge in unbridled relativism. ${ }^{7}$ Indeed, some important knowledge comes from the universalist tradition, including rejection of the relativist view that any language can only be described in its own terms, or the assertion that it is possible to identify a limited number of categories that are normally sufficient for reproducing those basic features of any human language related to human cognitive abilities in general.

Although there is theoretical disagreement as to how this happens, ${ }^{8}$ there is widespread consensus about the fact that humans live in a world that they structure through their cognitive abilities, and not just logically or visually, but also linguistically. We can sum this up somewhat succinctly in the words of Ernst Cassirer by stating that the categories of objects and events (Gegenstandsund Ereigniskategorien) are created only through language; in his innovative independent synthesis we can discern Humboldt's legacy:

Wenn es gelänge, eine Provinz des Seelischen aufzuweisen, die spezifisch mit der Sprache verknüpft und die wesentlich auf sie angewiesen ist, so ließe sich an ihrer Struktur vielleicht indirekt ein Zeugnis über das Werden und Wachsen der Sprache gewinnen - so ließe sich an ihrer Entwicklung vielleicht das Bildungs- und Gestaltungsgesetz, dem sie untersteht, in irgendeiner Weise ablesen. [...] Die These, die ich hier vertreten möchte [...], geht nun dahin, daß eine solche Provinz in der Tat besteht, insofern ein wesentlicher und

5 On mentalese see especially Fodor (1975) and Pinker (1994). The idea of a language of the mind, a lingua mentis, accompanies the entire course of western philosophical thought from antiquity to modern times. On those hard-to-imagine efforts that a language of the mind - if there were such a system - would have to perform (i.e., a universal conceptual system on which the meanings of the various individual languages are based) see Waltereit (1998, 9, orig. Ger.): “This system should encompass all possible concepts, should anticipate every conceivable conceptual development - otherwise the conception of linguistic meanings as reductions of a previously given stock of knowledge would not be tenable. It is very unlikely that this is the case."

6 See the more recent wave of works on linguistic relativity hypotheses: Gumperz/Levinson (1996), Lucy (1992, 1996 and 1997), Niemeier/Dirven (2000), Pütz/Verspoor (2000), as well as the more recent cognitively-based studies on language acquisition in general, e.g., Tomasello (2003).

7 While the extreme advocates of linguistic relativism did so, the father of this conception, Wilhelm von Humboldt, certainly did not.

8 See, e.g., Jackendoff's (2002) or Goldberg's (2008) critiques of Chomsky's conception of Universal Grammar (see, e.g., Chomsky 1993 and 1995) and the discussion of Hauser/ Chomsky/Fitch's (2002) theses in Pinker/Jackendoff (2005). 
notwendiger Zusammenhang zwischen der Grundfunktion der Sprache und der Funktion des gegenständlichen Vorstellens anzunehmen ist. [...] Die Sprache tritt nicht in eine Welt der fertigen gegenständlichen Anschauung ein, um hier zu den gegebenen und klar gegeneinander abgegrenzten Einzeldingen nur noch ihre 'Namen' als rein äußerliche und willkürliche Zeichen hinzuzufügen - sondern sie ist selbst ein Mittel der Gegenstandsbildung, ja sie ist im gewissen Sinne das Mittel, das wichtigste und vorzüglichste Instrument für die Gewinnung und den Aufbau einer reinen 'Gegenstandswelt'. (Cassirer 2004 [1932], 115f.) ${ }^{9}$

If it were possible to find a region of the mind which is specifically linked to language and which is essentially dependent on it, then perhaps its structure would indirectly bear witness to the emergence and expansion of language - perhaps it would be possible to read in its development the laws of formation and organisation to which language is subject. [.. . ] The thesis I would like to put forward here [. . . is that such a region does indeed exist, insofar as there is an essential and necessary relationship between the basic function of language and the function of the conception of objects. [...] Language does not enter into a world of fully-realised objectual representation to merely provide given clearly-delimited individual objects with 'names' as purely external and arbitrary signs but it is itself the means of object formation, the mediator par excellence, the most important and precious instrument for acquiring and constructing a pure 'world of objects'.

Certain basic structures of their cognitive abilities allow humans to organise the world - or what they perceive as the world - above all spatially and temporally. Some basic functions or categories of content recurring in the languages of the world can be found to be universal and they indeed correspond to these very general structurings. Although formulated by an early 20th-century philosopher of language, it is a view that is shared by more modern cognitively- and functionally-oriented theories, ${ }^{10}$ in which the most diverse linguistic structures - lexical and grammatical morphemes as well as more complex syntactic units - are understood as "mediators of meaning", as symbolic instruments.

9 For Cassirer, in no way does language only intervene in the domain of objective perception to assign purely externally and arbitrarily understood names to objects that are already given and determined by their reciprocal relationship. Rather, language intervenes actively, i.e., creatively, in establishing this process and reciprocally determining the objects. In Cassirer's view, what language in all its diversity does for people's lives can only be understood if we consider that it is not just a theoretical image of the world (as a mediator between subjectivity and objectivity, between mind and experience), but also a practical, moral and social image, the image of the ego and the other. The signifying communicative mechanism of language mediates between the mental and the sensual only at the dialogical moment. And this mediation gives rise to the domain of concepts, the will and objects.

10 These include, among others, the works by Croft (1991), Fauconnier (1984, 1999), Lakoff (1987), Lakoff/Johnson (1980 and 1999), Langacker (1987, 1991 and 1999) and Talmy (1985, 2000), as well as those (defined in some studies as functionalist) by Fillmore (1975, 1977 and 1985). See also the contributions in Geeraerts/Cuyckens (2007). 
Cassirer's humans live in a world of self-created signs and images, and each of their symbolic activities - for language represents only one of the "symbolische Formen” ('symbolic forms', see Cassirer 2001 [1923]) - has its productive function, as a form of objectification of the mind, and its hermeneutic function, as a form of understanding the world at the same time. In the view of Cognitive Semantics, humans also live in a similarly symbolically designed world: from this point of view, the creativity of language comes from the general tendency of humans, also active in other domains of cognition, to symbolise, in other words, to form categories which can then be combined (or expressed) in the various languages in particular patterns according to their individual rules, to form certain typical sentences or discourse schemas. In Tomasello's words, this can be summarised as follows:

[...] the Cognitive/Functional view sees language universals as resulting from human cognitive and social universals and the way languages have evolved. All groups of human beings have certain experiences they wish to communicate to others and have evolved the ability to use conventional symbols to do so. All groups of human beings have the ability to categorize these symbols and form combinations of them, and to extract schematic patterns of those combinations involving hierarchical organization. All groups of human beings engage in certain forms of social interaction and attention directing. All groups of human beings have the same vocal-auditory channel, which requires them to communicate their experiences by expressing symbols linearly, one at a time. Given these 'constraints', all groups of human beings have at their disposal some combination of four and only four linguistic devices for communicating experience: individual symbols (lexical items), markers on symbols (grammatical morphology), ordering patterns of symbols (word order), and prosodic variations of speech (e.g., stress, intonation) [...]. Different languages have evolved different ways of using these four linguistic devices in the service of specific communicative functions specific to the culture, and the evolution of particular languages shows a very interesting interplay between the 'choices' that are made. ${ }^{11}$ (Tomasello 1995, 150)

From this perspective, syntax - or grammar - and semantics cannot be seen as opposing each other: lexical, morphological and syntactic units are all symbolic connections, are the combination of form and content (meaning or function). ${ }^{12}$

This view, merely outlined here, I now also adopt in analysing the linguistic representation of conceptual structures and in dealing with the processes and

11 See Bates/MacWhinney (1982) and Slobin (1985), to whom Tomasello himself refers.

12 The idea of the inseparability of syntax (of grammar in general) from semantics (as opposed to Chomskian modularism) has been more recently advocated, especially in Langacker's model of Cognitive Grammar (1987). Langacker claims that morphological and syntactic structures are inherently symbolic, that is, they represent the organisation and symbolisation of the semantic content. Lexicon, morphology and syntax form a continuum of symbolic structures that are only separated arbitrarily and/or for practical reasons. 
patterns through which conceptual contents of a temporal nature are organised in language. Of course, I do so fully aware that it is only one possible view, one possible model, but one that proves to be particularly useful here. This does not imply that I question the value of other models, especially for semasiologically oriented investigations.

In the mechanism of reference - which determines this combination of form and content - a fundamental ontological distinction between objects and states of affairs is assumed. However, in this work I will not be concerned with ontologies in this sense, but will focus instead on analysing the symbolic ways of representing states of affairs, and will deal, in particular, with the symbolic representations of the content category of aspectuality that can be found in them. In explaining the phenomena dealt with here, it is assumed that language does not depict objective properties of states of affairs but rather conveys conceptualisations, i.e., the mental representations of states of affairs. When speakers act linguistically, that is, when they express a content for a communicative purpose through the means at their disposal, they represent states of affairs symbolically. Here, we assume that the unity of the sentence contains all the essential structures which serve to represent states of affairs. Indeed, at the sentence level, it is possible to accurately examine various basic linguistic functions - or the interplay of different and differently expressed formal content categories. ${ }^{13}$ For practical reasons, the sentence is chosen as the preferred unit in this study, although attention is frequently paid to the smaller units of syntagmas and the larger units of text, in which, of course, aspectuality is also found.

\subsection{Aspectuality and frames}

\subsubsection{Aspectuality and the levels of language}

This book deals specifically with aspectuality, with the general content category, which includes all the information pertaining to the internal temporal structuring inherent in a state of affairs - this is explained in more detail in this and the next chapter. The orientation of the investigation is - in accordance with the discussion in the previous section - cognitive-functional and onomasiological, and the conception of an "onomasiologie 'éclairée”" in the sense of Koch is adopted. It is

13 In general, it should be pointed out briefly that in linguistics, which deals with sentence semantics, a distinction is made between different levels of the sentence structure: the syntactic level, the semantic level (or level of thematic roles), the pragmatic level and the level of information structure. 
a view that does not regard the relations between mental and linguistic structures as direct, that is to say, as literal translations of one into the other; and a view that asserts the need to strictly control the efficiency of the onomasiologically chosen categories, including by analysing their uses in individual languages: ${ }^{14}$

La démarche onomasiologique est légitime à condition que l'on soumette sa grille descriptive à un contrôle sémasiologique. En d'autres termes: il faut considérer comme concept possible tout ce qui est désigné par un mot, ne serait-ce que dans une seule langue du monde. Toutefois, cela ne revient pas à dire que l'essence du concept soit forcément de nature langagière. Les mots des langues particulières ressemblent plutôt à des balises signalant des 'désignés' extra-langagiers qui les débordent largement du point de vue cognitif. (Koch 2003, 91)

The onomasiological approach is legitimate provided that the descriptive grid is submitted to semasiological control. In other words, we must consider as a possible concept everything that is designated by a word, even if it occurs in only one language of the world. However, this does not mean that the essence of the concept is necessarily of a linguistic [i.e., language-particular] nature. The words of particular languages instead resemble markers indicating extralinguistic designata that, from a cognitive point of view, largely extend beyond them.

Accordingly, in this work I examine the onomasiological model of aspectuality presented in Chapters 4, 5 and 6 - in terms of its efficiency in the study of individual languages through concrete examples, and apply it to Italian, French, Spanish and Catalan. This will allow us to look at the same time at some of the lexical and grammatical phenomena of Romance languages in a new light, including a) the so-called "telic states of affairs", a well-known issue in aspectological studies, b) the "perfective-imperfective" opposition of the past tenses prototypically treated there, and c) the numerous and diverse forms of verbal periphrases.

Such a complex category as aspectuality requires that it be analysed on different - but interacting - levels. In order to make the necessary differentiation

14 Koch, for his part, refers to Trabant's (1998) criticism of Pinker's (1994) mentalese. It has often been stressed that the onomasiological and semasiological perspectives can be very fruitful, not only in lexicology, and that onomasiological work does not necessarily mean abstract work remote from linguistic reality: "The prerequisites for semasiological examination of linguistic systems are suitable formal categories, for onomasiological examination they are correspondingly appropriate conceptual categories. Before any examination of the conjugation system of a given language, the categories by means of which this is to be undertaken must be examined. The most important postulate is that the categories used can be assigned to each other in a uniform system. This requirement has nothing to do with an attempt to press linguistic realities into the straitjacket of an a priori system: it is not about language, but about the categories used to investigate it in this first stage.” (Heger 1963, 6, orig. Ger.). 
between these levels for the investigation, I use an adaptation of Coseriu's (1981) subdivision of language levels (Ebenen des Sprachlichen) and distinguish between the following: ${ }^{15}$

a) A universal level of language (langage), of the human ability to speak, to refer, and the general contents, semantic categories and concepts that constitute the linguistic expression of reality. This level is usually concerned with complex semantic categories, functions that can be found in the most diverse languages and which are based on human cognitive abilities (such as the mechanisms of association and categorisation); it is their basic set of cognitive functions that allow humans to shape reality through perception and conceptualisation. These, therefore, are categories that are traditionally referred to, for instance, as "temporality”, “modality”, etc.; analogously, the term "aspectuality" is used here. ${ }^{16}$

b) A historical level, that of individual languages in their plurality as historical (dia-)systems, with their signifying and signified units, with their systems of relations, which represent a - historically created and given - realisation of the possibilities of the universal categories of the universal level of language a). In short, these are systems that result from operations of reference ${ }^{17}$ and the selection of different linguistic means - or the frequency of using such mechanisms - in the expression of the universal-language content. ${ }^{18}$ The grammatical and lexical categories, such as "tense”, "mode”, "aspect” and "Aktionsart”, of Italian, French, German, etc., are classified on this level.

c) An individual level of language, that of the concrete realisation of speech in discourse. This is therefore the level of practice, of concrete speaking in an individual language, which in turn represents the historical level of language b). It is driven by the communicative intentions of individual speakers.

The production and understanding of any aspectual information takes place in and through the interaction of all these levels, because the aspectual information

15 On this classification of language levels see also Koch/Oesterreicher (1990); see also Koch $(2003,87)$ for the subdivision of the linguistic vs. the extralinguistic-conceptual entity.

16 In some works, aspectuality is defined as a subcategory of temporality, since the distinction between deictic and non-deictic categories is subordinate there, see, e.g., Schwarze (1988). Here, not least for practical and explanatory reasons (i.e., to outline the subject of the investigation more precisely), the two content categories are treated separately.

17 Naturally, the operations of reference as such belong to the level of the activity of speaking.

18 On the historical level, Koch (1997) adds another important distinction, i.e., between the level of individual languages and that of the various discourse traditions. This cannot, however, be dealt with here. 
is diverse, complexly structured and combinable. Through speaking, speakers realise one or more of the possible combinations of these pieces of information in a concrete context; they do this to achieve the most diverse communicative goals through various communicative strategies (economy, expressivity, ...) and by using various pragmatic mechanisms (implicatures, inferences, ...). ${ }^{19}$

In order to provide a coherent explanation of aspectuality as a linguistic category, it is necessary to attend to the role of each of the various levels mentioned above and the locations of their interaction. However, it is equally necessary to maintain the separation of these levels and to stress that the analysis of aspectuality refers to the universal level of language a), while in looking at the aspectual systems of French, Italian, etc. we are referring to the historical level b). Finally, examination of how the interacting information which codifies the internal temporal structuring of a particular state of affairs is concretely verbalised in the utterance, how it is realised by the speaker by special means (forms, rules and strategies), is dealt with on the individual language level c).

\subsubsection{Frames as basic structures of the categorisation of reality}

This investigation is based on a special conception of human categorisation mechanisms for temporally structuring states of affairs. Therefore, of the various theoretical options available, a frame-based interpretation of aspectuality is chosen here. ${ }^{20}$ But before setting out the advantages of such an approach, let me first say a few words about frames as basic structures of the human categorisation of reality in general and the areas where the notion of frame may be applied.

Fundamental to frame theory are the now classic works of Fillmore (1975, 1977 and 1985) and Minsky (1975), ${ }^{21}$ who define the term "frame" as a special data structure created from memory "for representing a stereotyped situation" (Minsky 1975, 212), or as a structured "coherent schematization of [...] experience" (Fillmore 1985, 223). ${ }^{22}$ In other words, "frame" is understood as a

19 And this is rooted in the level of the activity of speaking.

20 In general, regarding the research that led to a new conception of the category in linguistics, see Berlin/Kay (1969), Rosch (1973 and 1977), Rosch et al. (1976) and Rosch/Mervis (1975). 21 Particularly important for the analysis of grammatical phenomena are the works by Langacker (e.g., 1987), who speaks rather of domain.

22 See also Barsalou's theory, popular in research on Artificial Intelligence (AI) and interesting for its dynamic conception of frames: "Because frames also represent the attributes, values, structural invariants, and constraints within a frame, the mechanism that constructs frames builds them recursively. The frame theory I propose borrows heavily from previous frame theories, although its collection of representational components is somewhat unique. Furthermore, frame 
structured and coherent knowledge context, which may be of a general conceptual or culturally-specific nature, by means of which humans address various everyday situations (making decisions, coping with problems, ...).

The most cited examples of frames include, on the one hand, the more culturally-specific, such as FLY (on board a plane) (see Handke 1995, 102), or RESTAURANT (VISIT) (Schank/Abelson 1977), in which various components interacting with each other can be recognised: locations (plane, ... or restaurant, ...), roles (pilot, passengers, ... or waiters, guests, ...), sets of actions (the passengers board the plane, the pilot flies the plane, ... or the guests are greeted by the waiter and escorted to the table, the waiter brings the menu, ...).

On the other hand, one of the more conceptual, more abstract examples of frames is the human conceptualisation of time and space (the notion of time and space belongs to human world knowledge).

In the last thirty years, in both Cognitive Linguistics and AI research, numerous studies have emerged that use the term "frame" as a very general model for knowledge contexts or experiential contexts of various kinds. ${ }^{23}$ Here, "frame" has been defined variously as static or dynamic, and frame models have been used to represent very different forms of the human conceptual organisation of reality, from the simplest to the most complex. The difficulties with such a theoretical model are not unstated. ${ }^{24}$

theorists generally assume that frames are rigid configurations of independent attributes, whereas I propose that frames are dynamic relational structures whose form is flexible and context dependent.” (Barsalou 1992, 21). In Romance research, see, especially, Blank (1997) and Koch (1999a and 2001a).

23 The variety of studies has, of course, generated a variety of terminologies: besides frame, there is scenario, schema, domain, script, etc. Generally, it should be noted that while terms such as frame and domain (Langacker 1987, 147) can be used to designate a static, abstract-conceptual situation, scenario or script is used to designate whole (communicative) processes. See Croft (1993) for domain, Schank/Abelson (1977) on the term script.

24 "Speakers and hearers have a common knowledge of the details of the restaurant visit; they do not need to make sure of this themselves, but can assume that the standard scene of the restaurant visit is known to both. But is this knowledge really a huge data structure with predetermined branches and defined terminal nodes that are able to establish contact with the environment or to embed subframes themselves? [. . . In everyday practice, however, it does not seem that it is the ability to reproduce stereotypical actions that is decisive, but on the contrary the ability to cope with situations in which the options for action cannot be derived from given instructions or even only from decision branches. [. . . ] In order to be able to depict the entire complexity of human experiential contexts, a frame theory would probably have to be able to fall back on a binding knowledge of the structure of cognitive processes. This is apparently hardly possible at the moment." (Waltereit 1998, 17, emphasis in the Ger. orig.). See also Konerding's (1993) critical remarks, quoted by Waltereit. 
Given that in the present work I am conscious of the difficulties pointed out here, the choice of a frame-based interpretation implies a general decision to conceive of the content category of aspectuality ${ }^{25}$ as a form of perception or conceptualisation, as a form of human conceptual organisation of temporal reality. ${ }^{26}$ Accordingly, among the many alternative terms, I choose here "frame", which is common in research. ${ }^{27}$ At the same time, a detailed model of the internal structuring of frames is rejected in favour of restriction to the intuitively plausible assumption "that experiential relationships are also an important principle of the organisation of knowledge and thus provide an environment in which referential indeterminacies can be disambiguated" (Waltereit 1998, 17, orig. Ger.).

In other words, it is merely assumed here that our perception and categorisation abilities recognise concepts and subconcepts in connection with each other and that they are stored thus in memory. It is also assumed that while, on the one hand, a frame is constituted only through the combination of its closely-related component parts, the individual subcomponents, on the other hand, ultimately acquire their configuration only within and against the background of the entire frame: frames consist of elements that are in contiguity with one another, they are networks of contiguity (Koch 1995, 1996a, 1996b, 1999a, 2001a, 2004 and 2012, Blank 1997, Waltereit 1998). But what exactly is meant by contiguity?

\subsubsection{Contiguity and the figure-ground effect}

One of the important basic theoretical assumptions of Gestalt psychology is that humans have the ability to group spatially or temporally related individual phenomena together as gestalts (see, e.g., Fitzek/Salber 1996, Herrmann 1976, Köhler 1947, Metzger 1986, Wertheimer 1925). ${ }^{28}$ It is well known that Cognitive Linguistics

25 In the case of aspectuality, in particular, it is not the variety of possible frame-relevant relationships that some critics consider difficult to manage and therefore arbitrary. Rather, it is two elementary and comparatively well-established relations: part/whole and temporal contiguity (see Chapter 4). On contiguity see Koch (2004 and 2012), Peirsman/Geeraerts (2006a), as well as Croft's (2006) position regarding the latter and Peirsman/Geeraerts' response (2006b).

26 Here, reliance is placed on the models of description and interpretation developed in Gestalt theory; see the following section.

27 For Romance research see Blank (1997), Detges (2001), Koch (1994, 1999a, 2001a, 2001b and 2004) and Waltereit (1998).

28 Of course, such observations had already been made before Gestalt psychology. Koch (2007, 11) reports how Aristotle, in the context of a theory of remembering, defines the three associative relations of similarity, contrast and contiguity. In the same essay, he tackles an important and exciting undertaking: he shows what Husserlian phenomenology can 
was also based on this fundamental idea of Gestalt psychology and dealt in different ways with what was formulated by the latter as the principles of perception: ${ }^{29}$ the principles of supra-summativity (Übersummativität), good Gestalt (also called the principle of salience), similarity and figure-ground effect. $^{30}$ Since here the figure-ground effect - which is closely connected with the principle of contiguity - plays an important role, ${ }^{31}$ these are discussed in more detail below.

When we assume that human perception and categorisation abilities recognise concepts and subconcepts in connection with each other - in the form of frames - and stores them thus in the memory, we also assume that these experiential contexts are a kind of cognitive added value, which is more than just the sum of the individual components of the respective frames. ${ }^{32}$

But how exactly are such elements related to each other, i.e., how can this connection of concepts - of gestalts - be described? Many of the gestalts, the

contribute to the constitutional analysis of language (see Husserl 1993 [1922] and 1995 [1929]). Koch resorts to this approach, on the one hand, and Gestalt psychology, on the other, to give a non-mechanistic interpretation of the associative relations (which are now of central importance in Cognitive Linguistics). In this context, he also refers to the work of Holenstein (1972), whose merits he points out - and not only for his interpretation of Husserl's phenomenology.

29 In particular, Cognitive Linguistics also deals with the connection between these principles, the conceptualisations that underlie them, and the strategies through which they are realised verbally.

30 On "Wertheimer's Figures" and other well-known images from Gestalt psychology which illustrate these principles graphically, see, among others, Wertheimer (1925), Holenstein (1972), Raible (1983), Blank (1997 and 2001), Metzger (1986), Rubin (1921) and Wittgenstein (1995).

31 In general, this principle plays a central role in Cognitive Linguistics - and especially in the context of construal problems: see, among others, Croft/Cruse (2004), Langacker (1987), Talmy (2000) and Ungerer/Schmid (1997). Incidentally, in this work I make little reference to Croft's latest book (2012), as it was only published after I had developed the model presented here. Still, I would like to point out an important difference between the models: Croft also deals with the idea of boundedness in the constitution of states of affairs, but, unlike my model, his does not take a purely aspectual perspective and offers a so-called two-dimensional analysis. He suggests distinguishing between qualitative boundedness ( $q$-boundedness) and temporal boundedness ( $t$-boundedness): "In sum, the property of boundedness that is considered to be a part of the root of the verbal meaning, i.e. the existence of a natural end point or telos for the event, is represented by the states defined on the q dimension, while boundedness of a particular event in a particular occurrence is defined by the existence of profiled beginning and ending phases on the t dimension.” (Croft 2012, 81).

32 See, among others, Fauconnier (1984 and 1999), Goldberg (1995 and 2006), Lakoff (1987) and Langacker (1987, 1990 and 1991). 
situations of everyday human life, are indeed structured in a very complex way: in these conceptual structurings, similar items are perceived and grouped together as a figure and it is only by contrast that this figure is distinguished from other figures which then recede into the background. When grouping elements into larger contexts, what matters is visual or conceptual proximity, so that what has been grouped as a figure (in contrast to the ground) and what as a ground (in contrast to the figure) lie close to one another. This is exactly what is meant when we speak of the principle of contiguity: gestalts and concepts that come into contact spatially, temporally and logically with each other. Between the gestalts in contact - represented as figure and ground - there can be an interplay, which has been called the "figure-ground effect". Figure (1), which shows either a white cross on a dark background (to which the white figure is related) or a dark cross on a white background (to which the dark figure is related), represents the contiguity between white and dark elements as well as the interplay between what is the role of the figure and the role of the ground; because only one of them can be the figure (perceived as a cross) and one of them the ground - they cannot both be seen at the same time: ${ }^{33}$

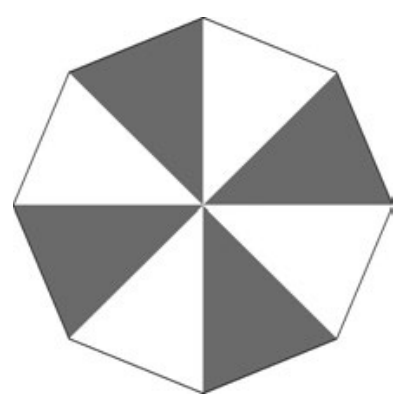

Fig. 1: Representation of the figure-ground principle, after Wittgenstein $(1995,541)$.

On a more abstract level, these types of visual representation (and others) make it possible for those figure-ground effects that are induced by contiguity to also be imagined within frames, as frames are composed of elements which are

\footnotetext{
33 If we follow Koch's terminology (2007 and 2008), inspired by Husserl (1993 [1922]), and Holenstein's interpretation (1972), to explain the mechanisms of contiguity, we can also explain such mechanisms from a different theoretical perspective and talk about "presented" and "appresented" components in categorisation: in our perception, besides "presented" components (which represent the thematic core), other "appresented" components are evoked, which are contiguous to the "presented" ones and which form the opened "horizon" around the thematic core.
} 
related by contiguity. In fact, the contiguity relation that keeps the frame together allows the figure-ground effect within a frame to be seen in the form of a re-perspectivisation, a change in the windowing of attention. Two main types of figure-ground effects can be distinguished, those generated between the individual elements of a frame and those generated between each of its constitutive elements and the frame as a whole; these are illustrated in Figures (2) and (3), respectively:

Frame

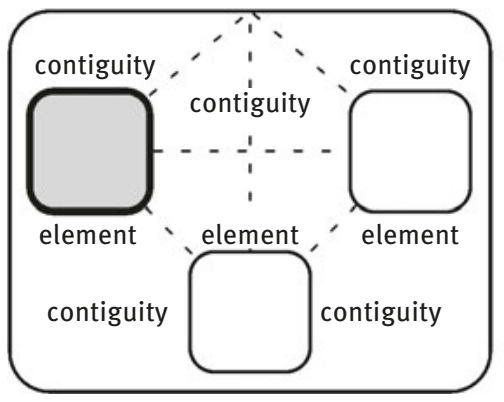

Frame

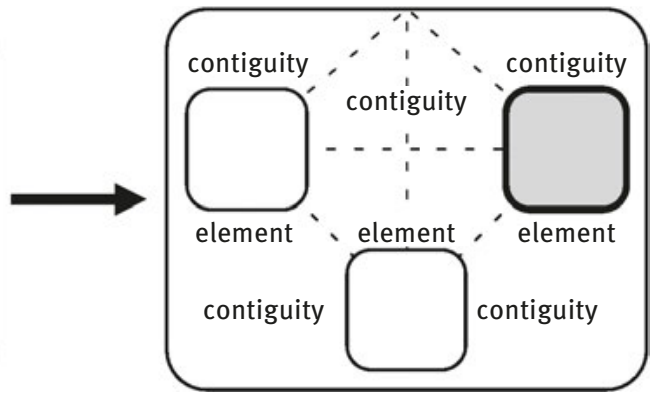

Fig. 2: Figure-Ground Effect I, after Koch $(2012,267)$ with modifications.

Frame

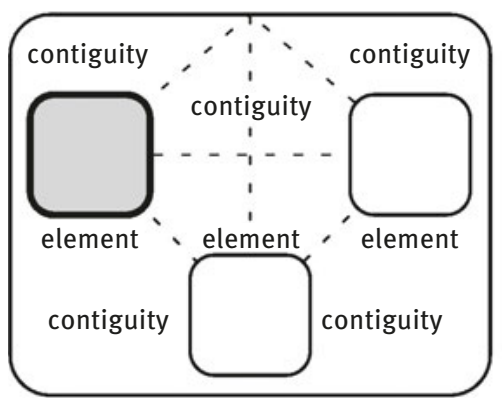

Frame

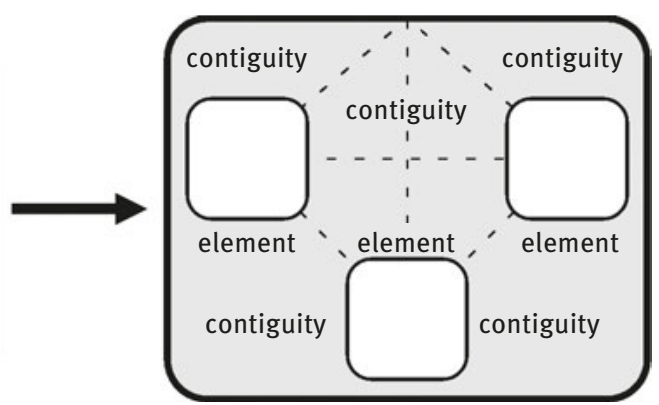

Fig. 3: Figure-Ground Effect II, after Koch $(2012,267)$ with modifications.

These (re-)perspectivisations - known as "windowing of attention" or "highlighting" - have been used very successfully in Cognitive Linguistics research to describe various linguistic phenomena (see, among others, Taylor 1995, Croft 1993, 
Ungerer/Schmid 1997, Talmy 1996 and 2000, especially Chapter 4). The present work will also move along this line: in the next section I build a bridge between contiguity relations/figure-ground effects in the frame and aspectuality, in which various areas of linguistic application of the frame concept are presented.

\subsubsection{Areas where the notion of frame can be applied}

The notion of frame has numerous applications, and plenty of advantages follow from the decision to adopt a frame-based theory (see, in particular, Lee 2001, 8ff., to which I refer in the following). A frame is a multidimensional concept with a conceptual and a social dimension that also allow for a fruitful treatment of certain forms of polysemy. ${ }^{34}$ At the lexical level, we can see that a lexeme is connected in various ways with many different frames that represent the contexts, the experiential connections, in which the speaker has learned it and uses it. In each of these contexts, one of its meanings is highlighted through its combination with the other elements in the frame: in other words, these are somehow conceptually in contact (e.g., metonymically related to each other and held together in our frame-structured experience, our world knowledge), rather than being derived from an assumed "core value" of the lexeme. For example, when trying to explain the meaning or different meanings of a lexeme such as "sister", that might best be done by showing how the different meanings emerge in different frames: a) in the "biological frame" (in which it is the daughter of the same mother); b) in the "social frame" (in which it is, for example, a very close friend who is perceived as being like a sibling; c) in the "professional frame" (a nurse) or d) in the "vocation frame" (a nun), etc. ${ }^{35}$

However, it is not just to the meanings of individual lexemes of the type described above that such a model can be applied; good use can also be made of a similar representation and interpretation model to analyse the linguistic structuring of temporal - and here, especially, aspectual - contents of entire

34 On the conception of polysemy in Romance research, see especially Blank (1997), Koch (1999c, 2001b and 2005) and Marzo (2013).

35 See also the possibilities of analysing a lexeme like weekend (Fillmore 1982, 119). In other words, this is the old problem of connotation, which, however, can be better understood with the frame concept than in formally-oriented models. Our world knowledge structured in different frames contributes to understanding the meaning(s) of lexemes, such as when, for example, two different lexemes designate the same phenomenon (meaning that the referent/ phenomenon is stored with two different frames for two different uses). 
states of affairs with similar advantages, as analysis of the following examples shows:

(1) Ger. Der Regen fiel [Prät.] langsam zu Boden. 'The rain fell slowly to the ground.'

(2) Ger. Die Feder fiel [Prät.] langsam zu Boden. 'The feather fell slowly to the ground.'

States of affairs such as those presented in examples (1)-(2) have different aspectual contents, which are defined here firstly in traditional terminology. While (1) represents a telic, durative, but reiterated state of affairs, in (2) we have a telic and unique state of affairs. This interpretation is related to the combination of the verb fallen with the respective first arguments: based on his/her encyclopaedic knowledge, the speaker is aware that the falling of a feather attracted by gravity is a non-recurring process (the falling of a single feather, which has a clearly defined individual reference), while the falling of the collective noun "rain" means the falling of many, light, dense, etc. raindrops. A semantic explanation of the words and structures of language, which understands these not as simple, immediate expressions of concepts (with which they would then also have a 1:1 equivalence), but as tools that trigger in speakers and hearers activation of certain areas of their world knowledge depending on the context ${ }^{36}-$ i.e., a semantic explanation of words and structures of language, which takes into account human encyclopaedic knowledge - has the enormous advantage of being able to deal comprehensively with historical (language change) and socio-cultural factors of communication.

At this point, however, further clarification should be given, which sheds light on the application of the notion of frame in this investigation. Of course, relatively concrete frames can be used to explain linguistic phenomena, and research in this field has for the most part done precisely that (see the analysis of the frames RESTAURANT and SISTER above). However, to explain certain linguistic problems requires more abstract frame models that represent whole classes of frames (this is the case, for example, in Talmy's typology of motion verbs). ${ }^{37}$ The aspectuality frames discussed here will now be classified on a comparable abstract level (Chapter 4 presents a more detailed discussion).

36 Here, different areas are activated to varying degrees in different contexts of use.

37 Talmy (2000, esp. Chapter 2) does not analyse individual motion processes, but only elements of a very abstract MOTION event-frame: MOTION, PATH, MANNER, etc. 
If frames consist of elements related by contiguity, aspectuality consists of elements which are related via special forms of contiguity. In explaining phenomena such as "perspectivisation" within a situation frame or a "windowing of attention", in particular, ${ }^{38}$ the notion of frame has, according to Koch (2001a, 202f.), ${ }^{39}$ proved particularly fruitful.

\subsubsection{Aspectuality and situation frames - a first definition}

The present study of aspectuality ${ }^{40}$ is based on results drawn from cognitivelyoriented semantics ${ }^{41}$ in that it conceives of states of affairs, which are the expression of this content category, as situation frames and retains the concept of "perspectivisation within a situation frame", which proves to be particularly useful, especially in explaining the mechanisms underlying aspectuality. It seems to be no coincidence that this idea of perspectivisation, in particular, has also been traditionally associated with aspectuality: in 1829, Reiff introduced the French term aspect (from the Latin aspicere 'to watch', 'to observe') as a translation of the Russian vid. ${ }^{42}$

The particular conception of aspectuality that results from such a perspective will be further clarified on the following pages and in subsequent chapters, but first I give here a short, very general definition:

38 On "perspectivisation", "highlighting" and "windowing of attention" see, among others, Croft (1993), Dirven et al. (1982), Fillmore (1977), Talmy (1996 and 2000), Taylor (1995) and Ungerer/Schmid (1997). More recent publications on Cognitive Linguistics in general include Croft/Cruse (2004), Evans/Green (2006), Geeraerts (2006) and Geeraerts/Cuyckens (2007).

39 The "process of perspectivisation within frames" (Koch 2001a, 203) could be spoken of from an onomasiological as well as a semasiological point of view. In the first case, "one raises the [...] question of how different perspectives of a frame are expressed linguistically"; in the second case, the problem is whether different uses "of a given linguistic expression correspond to different perspectives within the same frame" (Koch 2001a, 203).

40 See Chapter 2 on the history of the notion of aspectuality and the different ways it can be understood.

41 For a general introduction to Cognitive Semantics, see, among others, Lee (2001), Taylor (2002) and Ungerer/Schmid (1997). Given the Romance orientation of his work, reference is also made here to Blank (1997 and especially 2001).

42 On the etymology of the term as well the history of the category in general, see Pollak (1960 and 1988); see also §1.2.3. 
Aspectuality is the universal content category through which speakers linguistically structure the manner of the development and the distribution of a state of affairs in time; it contains that complex of information which relates to the temporal structuring of a given state of affairs, independent of any reference to the point of speech.

Definition 1: Aspectuality

If aspectuality is defined here as the internal temporal structuring of a state of affairs conceived as a situation frame, ${ }^{43}$ then the relations between the elements of this situation frame or between the frame as a whole and its constitutive elements are defined as relations of contiguity. These constitutive elements can now be focussed within the situation frame, i.e., perspectivised (see §§3.2.3-3.2.4). According to what is placed in the foreground, aspectuality can be subdivided into three dimensions, three perspectives: the external aspectuality of a state of affairs or its absolute delimitation; the adjacency-related aspectuality of a state of affairs or its relevance for its (direct) environment; the internal aspectuality of a state of affairs or its further internal subdivision (for a complete representation see §4.4).

This means, on the one hand, that the investigation uses a very abstract frame model to represent aspectuality, while, on the other hand, it offers no complete analytical model of states of affairs in general, as is often the case in frame theory. Rather, the investigation is focussed exclusively on a single level, namely, the aspectual or internal-temporal. Accordingly, graphic representations of specific frames are designed for this level (see Chapters 4 and 5).

The category of aspectuality is understood in this work as:

- semantically homogeneous in the sense of unidimensional approaches (see §2.4);

- universal, in the relativised sense above;

- complex, composed in a sense that is not purely mathematically additive nor compositional, but corresponds to the structures and dynamics of constellations;

- based on a few homogeneous abstract criteria, mainly based on the principle of temporal delimitation;

- realised on the various levels of the language system, i.e., by different organisational principles (morphological, syntactic, etc.) using different

43 The diachronic perspective, in particular, which is facilitated by the excellent documentation of the Romance languages, enables insights to be made into the cognitive basis of aspectual delimitation, since semantic change is based on cognitive processes. See, among others, Blank/Koch $(1999,1)$ and Sweetser (1990, 45f.). 
linguistic means (lexical or grammatical), and, of course, in a variety of ways on the level of individual languages.

To further elucidate all these points - also on the basis of the model designed we will now follow in detail the path that led to this definition and outline its theoretical assumptions and its consequences. In the next chapter, the model of the classification of aspectual content developed on the basis of these theoretical assumptions will be presented in detail.

\subsection{Semanticity - abolishing the semantic distinction between aspect and Aktionsart}

I argue in this work that language-particular categories are not suitable for comparative studies (see Haspelmath 2007, 126 and also Chapter 2 of this work). In agreement with Bybee (1985), Bybee/Perkins/Pagliuca (1994), Smith (1991) and many of the more recent works on TMA (tense/mode/aspect) categories, ${ }^{44}$ I assume that the expression of aspectual contents is not language dependent but crosslinguistic and is based on human cognitive abilities, ${ }^{45}$ which are responsible for the temporal structuring of states of affairs. Therefore, a more general, abstract semantic category called "aspectuality" or "aspectual delimitation" is assumed here, which subsumes all the possibilities that the various historical-natural languages have at their disposal to express, through different means, temporal structurings of states of affairs. With regard to aspectuality, in order to explain exactly what is meant by "semantic" or "content category" here, and in a large part of the literature on the aspectual domain, and thus also to prevent any possible terminological misunderstanding, ${ }^{46}$ one important distinction is to be borne in mind, i.e.,

44 See, among others, at least Dahl (1985 and 2000), Hopper (1982a), Talmy (2000) and Thieroff/Ballweg (1994-1995). Terminologically, it should be noted (as discussed in Chapter 1 in more detail) that these works often use the term "aspect" even in referring to what is called "aspectuality" here, namely, the general aspectual domain and not the category marked grammatically on the verb. On this, see also Sasse (2002).

45 "I will assume that the aspectual categories are not language dependent, but are based in human cognitive abilities.” (Smith 1991, xvii).

46 Koch (1996a) emphasises that although, on the one hand, conceptual, extralinguistic knowledge was disregarded in Structural Semantics, in Cognitive Semantics, on the other hand, the individual-language character of linguistic signs, i.e., the existence of the semantics of an individual language, was misjudged. In its synthesis, Raible's semiotic model offers, according to Koch, the possibility to address the central problems of both theories. 
that between crosslinguistic-conceptual and language-particular meaning. ${ }^{47}$ For this purpose, Raible's (1983) semiotic model is used: ${ }^{48}$

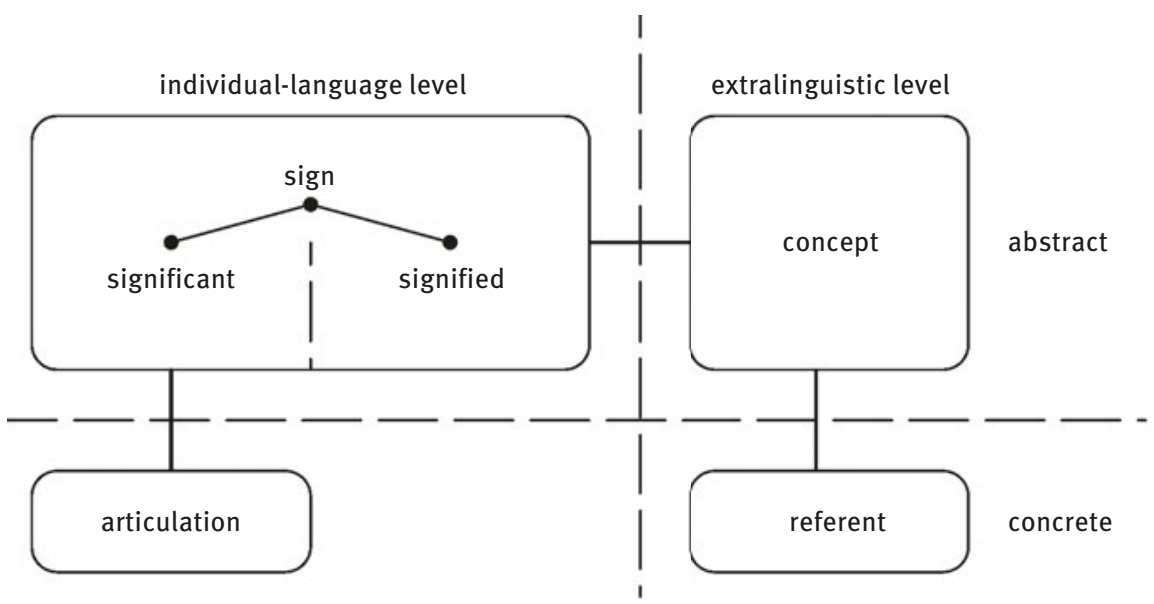

Fig. 4: Semiotic model, Blank (2001, 9) after Raible (1983).

Two important distinctions underlie this semiotic model: that between a concrete and an abstract level, on the one hand, and that between an individual-language level and an extralinguistic level, on the other hand. This can be represented in the form of a cross-classification, because the overlapping of these criteria gives rise to a language-particular concrete entity (the articulation), a languageparticular abstract entity (the linguistic sign), an extralinguistic concrete entity (the referent) and an extralinguistic abstract entity (encyclopaedic knowledge, the concepts). The linguistic sign, in turn, consists of a linguistic form (the significant), language-particular phonological knowledge, a content (the signified) and sememic knowledge (of the language-particular semantics).

When speaking of aspectual content or information here, I am referring, in particular, to the extralinguistic - that is, the conceptual, cognitive, universal, or crosslinguistically understood - structuring of states of affairs. Aspectuality defined in these conceptual, abstract and universal terms is located on a completely different level to that of aspect and Aktionsart, which are understood as the specific (grammatical or lexical) categories of individual historical languages and

47 On the possible types of relation between concept (extralinguistic and universal world knowledge) and linguistic meaning (language-particular world knowledge), see Waltereit (1998, 7ff.).

48 This is an adaptation of Blank's (2001) model, which shows some terminological innovations compared with Blank (1997). 
which are bound to the semantics of a particular language. An onomasiological treatment of the general content category of aspectuality is therefore expressed first and foremost in its universal-semantic view, which must go beyond any interpretative framework that emerges from historical facts and analyses of individual languages. ${ }^{49}$

If we now acknowledge that aspect and Aktionsart are homogeneous in terms of content on a universal semantic level, ${ }^{50}$ i.e., when they are subsumed in a superordinate category of aspectuality, then they differ only in the fact that one is a grammatical category, the other a lexical one. And this distinction can be of use only in the context of a semasiological, language-particular investigation, which describes the distribution of the possibilities of expressing aspectual information in the particular language considered, and is based not least on the separation of grammar and lexicon, a stance strictly followed in traditional research. ${ }^{51}$ However, if the general aspectual domain is considered from an onomasiological perspective, then the traditional non-semantic distinction between aspect and Aktionsart ceases to be relevant. An insistence on this distinction ${ }^{52}$ would lead to circular conclusions, since, after losing the differences in content described above, the only difference remaining is the definitional difference, which is self-evident. ${ }^{53}$ Thus, an investigation that

49 See $\S 1.2 .3$ for a history of the discovery and the terminological and definitional specification of the verbal categories "aspect" and "Aktionsart".

50 In the traditional literature on aspect and Aktionsart, the semantics of these two timestructuring verbal categories is also frequently discussed, and even opponents of the "dangerous mixing" of them - commented on in detail in Chapter 1 - recognise the undeniable semantic connections, the clear similarity between aspect and Aktionsart. See, e.g., Bertinetto (1986, 82ff.) and Pérez Saldanya (2002, 2602).

51 It has already been pointed out in Chapter 2 how recent typological research has shown that the distinction between the grammatical and lexical elements of language is not necessarily to be seen as a distinction between rigid, discrete categories, but as one between elements on a continuum; see, among others, Bybee (1985), Dahl (1985 and 2000), Hopper/Thompson (1980) and Talmy (2000). See also the research on grammaticalisation in general, including Ch. Lehmann (1995), Hopper/Traugott (2003), Haspelmath (1998), Lang/Neumann-Holzschuh (1999), Detges/Waltereit (2002), Detges (2004), Marchello-Nizia (2006) and Klump (2007). See, furthermore (and synchronically), the studies in Construction Grammar, including the anthologies by Fischer/Stefanowitsch (2006), Stefanowitsch/Fischer (2008) and Lasch/Ziem (2011).

52 Coseriu $(1987,125)$ emphasises that this is a distinction on the status-relational level and not the semantic level, and explains how many misunderstandings and confusions have arisen precisely for these reasons in dealing with the category aspect.

53 It is self-evident, since the argumentation is often as follows: aspect is defined as a grammatical category, Aktionsart as a lexical one. Aspect and Aktionsart are therefore different categories, which is proved by the fact that aspect is expressed grammatically and Aktionsart lexically. 
advocates the semanticity of aspectuality must relativise a distinction that is based on the criterion of grammaticality vs. lexicality and must be carried out from a semasiological perspective. ${ }^{54}$ From an onomasiological perspective, the most interesting point is the description of the content, and only in the second instance the verbalisation of this content by different means. Of course, this does not mean - and I would like to stress this point - that it is not possible nor useful to divide the linguistic signs of the world's languages into two subsystems: open or lexical classes and closed or grammatical classes (see, e.g., Talmy 2000, I, 20ff.). Nor does this mean that from a semasiological and individual-language (such as Russian) perspective the question of what weight should be given to the form cannot be answered otherwise, much less that lexical and grammatical forms of realisation are absolutely identical.

\subsection{Universality - cognition and the crosslinguistic perspective}

If, now, we start from the above-described perspective of the semantic homogeneity of the aspectual domain, it must be possible to identify a criterion on which the various representations of aspectual information are based and by which they can be explained. Such a criterion must justify the aspectuality of the various types of information - traditionally divided into aspect and Aktionsart - in their similar semantic content, while at the same time serving to subclassify these types of information. The criterion in question must be specific and precise enough to describe the plurality of the content-related (that is, semantic) and non-formal ${ }^{55}$ presentation of aspectuality. At the same time, it must be general enough to be able to find correspondence in the various languages of the world, to permit comparative linguistic investigations, and to serve effectively as a tertium comparationis. Therefore, it must be sought at the level of the universal cognitive abilities of humans, at the level of conceptualisations.

Aspectuality, then, is of course manifested differently in the various individual languages in terms of the selection of the methods they use to express it and the quantitative and qualitative distribution and differentiation of such methods and their interaction. Those aspectual contents, which are expressed in one language by a complex inflectional system, can indeed be expressed in another language by

54 This distinction can also be based on a special conception of grammar, see, e.g., Ehrich (1992) and Smith (1991).

55 This means, then, that it seems secondary whether aspectual contents are expressed by morphological, syntactic or lexical units. 
lexical means. ${ }^{56}$ This is particularly striking when comparing Romance languages (Italian, French and Spanish in the following examples) with German. With regard to the temporal delimitation and non-delimitation of states of affairs, these languages express the same (general) aspectual meanings either by grammatical or by lexical markings:

(3) It. Leo seppe [Perf. Sem., compl./perf. inflectional marker] la notizia dalla bocca di Julia.

'Leo came to know the news from Julia's mouth.'

(3') It. Leo sapeva [Imp., incompl./imperf. inflectional marker] la notizia dalla bocca di Julia.

'Leo knew the news from Julia's mouth.'

(4) Fr. Léo sut [Pass. Sim., compl./perf. inflectional marker] la nouvelle par la radio. 'Leo came to know the news from the radio.'

(4’) Fr. Léo savait [Imp., incompl./imperf. inflectional marker] la nouvelle par la radio.

'Leo knew the news from the radio.'

(5) Sp. Leo supo [Perf. Sim., compl./perf. inflectional marker] la noticia de la boca de Julia.

Leo came to know the news from Julia's mouth.'

(5’) Sp. Leo sabía [imp., incompl./imperf. inflectional marker] la noticia de la boca de Julia.

'Leo knew the news from Julia's mouth.'

(6) Ger. Leo erfuhr [Prät., compl./lexical marker] dies aus Julias Munde.

'Leo came to know this from Julia's mouth.'

(6') Ger. Leo wusste [Prät., incompl./lexical marker] dies aus Julias Munde. 'Leo knew this from Julia's mouth.'

In the Romance examples (3)/(3')-(5)/(5'), the so-called "perfective" (Passato Remoto, Passé Simple, Pretérito Perfecto Simple) and "imperfective" (Imperfetto,

56 See Chapter 5 for a contrastive linguistic analysis which deals with such cases in more detail. 
Imparfait, Pretérito Imperfecto) verbal inflection markers appear to express states of affairs that are, respectively, (punctually) delimited and (duratively) non-delimited. In the German examples (6)/(6'), on the other hand, these different temporal structures are expressed through different semantic information contained in the verb stem (in (6) erfahren 'to come to know' and in (6') wissen 'to know') although the verbs bear the same inflectional markers (past tense). The temporal structures are therefore communicated lexically by the so-called Aktionsarten: according to the traditional terminology based on Vendler (1957), erfahren is a transformative verb or an achievement (punctual or non-durative, telic, dynamic), and wissen a stative verb (durative, non-telic, non-dynamic).

Aspectual information can therefore be imagined as "conceptual building blocks" of an aspectual nature, as basic conceptualisations of the internal temporal structuring of states of affairs. These basic conceptualisations are located on a universal level, which seems adequate for the needs of an onomasiologically-guided analysis. These aspectual building blocks, as already stated above, can then be packaged differently in the linguistic material - grammatically or lexically - as the comparison between examples $(3) /\left(3^{\prime}\right)-(5) /\left(5^{\prime}\right)$, on the one hand, and (6)/(6'), on the other hand, shows. They can also be packaged differently in so far as they are expressed as a cluster or as syntagmatic material: regardless of whether a given state of affairs is presented as in (7) or in (8), it contains the same aspectual content, has the same internal temporal structure: ${ }^{57}$

(7) It. Ho appena mangiato [Perf. Com.].

'I have just eaten.'

(8) Fr. Je viens [Prés.] de manger.

'I have just eaten.'

There is no doubt that the combinations and hierarchisations of individual aspectual contents - which are called "basic conceptualisations of aspectuality" here - are very different. However, aspectuality can be found in all the world's languages, all - or almost all - have developed means of expressing aspectual content. $^{58}$ In other words, it is a universal phenomenon displaying languageparticular manifestations (see Bybee 1985, 2). ${ }^{59}$ In choosing a cognitive approach

57 See here Talmy's important contributions to the categorisation of linguistic structures in general and motion verbs in particular; a complete collection can be found in Talmy (2000).

58 See Dahl (2001) for an analysis of the so-called languages without aspect.

59 "Aspect is a parameter which is realized differently across languages." (Smith 1991, 3). 
this work distances itself from De Miguel's (1999) likewise onomasiological study (see §2.3.1) with regard to an important issue: here I propose extending the investigation towards defining the cognitive operations which underlie the aspectual structuring of states of affairs. ${ }^{60}$

\subsection{Complexity - the structuredness of the category and the interplay in the sentence}

Another central step in this approach to aspectuality consists in viewing it as a complex category. What exactly is meant here, and above all, what is not meant here - i.e., that aspectuality is not based on a purely additive mathematical principle of composition - is further specified and explained in what follows as well as in subsequent chapters through the analysis of different representations of states of affairs. Yet, I will make some essential remarks at this point:

We speak of a complexity of aspectuality on two levels:

- on the level of the onomasiological foundation, the structuring of the category as such;

- on the level of the convergence of the diverse elements by which aspectuality is realised in concrete sentences. ${ }^{61}$

In Chapters 4 and 5, in presenting the model of aspectuality, which describes certain very abstract types of perspectivisations in situation frames, I will show what is meant by "complexity" or "constellation-ness" in the sense of a): the interplay between the different options in external, adjacency-related and internal aspectuality. Undoubtedly, it is this discussion of complexity on the level of the onomasiological foundation of the category as such that constitutes the focus of this investigation. We will have to look for an explanation of complexity which has nothing to do with compositionality in the sense of Frege or with the convergence of different elements in the sense of Construction Grammar, since both are compositional principles that are certainly well suited for analyses on the level of the interplay of elements in the sentence, but not for those

60 On Gestalt rules and association principles in general, see Herrmann (1976) and Metzger (1986); see also Blank (2001, 43), Croft/Cruse (2004), Koch (1999a and 2012) etc.

61 This corresponds to the onomasiological perspective chosen here. However, work in this field rarely takes an onomasiological perspective in looking at how the content category of aspectuality is linguistically expressed, but looks instead at the semasiological question of the nature of aspectuality as the sum of the individual elements in the interpretation of sentences. 
on the purely conceptual level of a - not yet formally expressed - content category.

On the following pages, however, I first discuss what is meant by complexity in the sense of b), in other words, what are the elements that serve the expression of aspectuality in a sentence and what happens between these elements.

The aspectual structuring of a state of affairs conceived as a situation frame is expressed in a complex way, in that it is expressed in the sentence by very different subcomponents interacting with one another. These can convey aspectual contents directly or only influence them, and they can be found at different organisational levels (lexical, morphological, syntactic, ...).

If we address the question of what the elements that serve to express aspectuality in the sentence are, we first of all find the verb, traditionally the central issue in research on aspect. As regards the analysis of aspectual information from a semantic-functional perspective, the verb is undoubtedly central as far as semantics is concerned. However, consideration of aspectuality in the verb stem alone and in isolation merely provides information about the potential of the verb in question, because what constitutes this centrality is the constitutive function of the verb valence in the sentence semantics. So, if one goes beyond the notion of verb valence in the analysis of aspectual information as well, there is certainly no point in speaking of aspectuality expressed solely through a verb ${ }^{62}$ without involving its participants and its environment.

The need for an analysis that can accommodate the possible combinations of the verb and its arguments was advocated by Verkuyl in the 1970 s. ${ }^{63}$ He was the first to emphasise - and was critical of theoretical lines that did not - that the aspectual information contained in the verb stem differs depending on its arguments, and that in order to interpret it correctly it must be considered in the verbal syntagma. ${ }^{64}$ How the aspectual behaviour of most verbs changes depending on the realisation of one or another of their arguments in the utterance is shown by the following examples, which are described using the traditional terminology of Vendler's verb classifications:

62 Of course, it would make even less sense to speak of the aspectual nature of a verb. This investigation - which does not intend to offer any verb classification, even though this is certainly very valuable in other contexts - is not concerned with ontology. As the differences between the various aspectual contents cannot be ascribed to the states of affairs themselves, I prefer to keep to presenting or describing the states of affairs.

63 His 1993 monograph continues his work on aspectuality begun in the seventies and modifies several points of his theory.

64 See also the advocates of this position in Slavic research: Anstatt (2003) and V. Lehmann (1992, 1997 and 1999). 
(9) It. Leo bussò [Perf. Sem.] alla porta. [punctual: non-durative + non-telic] ${ }^{65}$ 'Leo knocked on the door.'

(9') It. Leo bussò a lungo/tre volte alla porta. [punctual + iterative] 'Leo knocked long/three times on the door.'

(10) Fr. Léo mange [Prés.]. [durative + non-telic] 'Leo eats.'

(10’) Fr. Léo mange une pomme. [durative + telic] 'Leo eats an apple.'

(11) It. La pioggia cade [Pres.] leggera sulla terra. [durative + non-telic] 'The rain falls lightly on the ground.'

(11') It. Il sasso cade pesantemente nell'acqua. [non-durative + telic] 'The stone falls heavily into the water.'

(12) Sp. Leo encontró [Perf. Sim.] una seta en un bosque de pinos. [non-durative + telic]

'Leo found a mushroom in a pine forest.'

(12') Sp. Leo encontró setas en un bosque de pinos. [non-durative + telic or durative + non-telic]

'Leo found mushrooms in a pine forest.'

In all the cases listed above, the verb can be assigned to one or the other so-called actional class, depending on whether:

- as in (9) and (9'), an adverbial expressing durativity or quantification (here a lungo or tre volte) is present in the sentence or not;

- as in (10) and (10'), a second argument (here a direct object, une pomme) is present in the sentence or not;

- as in (11) and (11'), the first argument (the subject) is a collective group noun $^{66}$ or a count noun (here, respectively, la pioggia or il sasso);

65 This sentence can also be interpreted as reiterative, which already in this context speaks for polysemy of the verb.

66 For a classification and interpretation that - besides count/mass nouns - also takes into account so-called group and generic nouns, see Mihatsch (2006). 
- as in (12) and (12'), a second argument in the sentence is present with singular or plural quantification (indefinite-specific, in this case una seta or setas).

This verb classification, which is determined contextually, is undoubtedly the prevalent position in aspectological research today. However, the influence of other elements in the sentence on the aspectual value is rarely taken into account, ${ }^{67}$ nor is the impact of extralinguistic and pragmatic factors, such as the iterative and/or habitual interpretation in the case of the logically contradictory combination of punctual Aktionsarten with an imperfective aspect or, as seen above, with adverbials expressing durativity. Verkuyl's more recent works (see Verkuyl 1993) - onomasiologically oriented and formally implemented - are mainly concerned with the verb and its arguments and deal only marginally with the influence of the other elements in the state of affairs, yet these are of great relevance in the present study: ${ }^{68}$

It is precisely in 'the linguistic tradition in the first half of this century', [. . . ] that aspectologists have become conscious of the fact that a pure morphosyntactic approach to aspect falls short of recognising the importance of the interaction between the organisation of the verbal lexicon and the aspect markers and/or aspectual interpretation cues operating on the morphosyntactic level. (Sasse 2002, 220)

The aspectual interpretation of a state of affairs - the view advocated here thus results from a much more complex interaction of several elements or subcomponents in the state of affairs understood as a frame. Even the elements that do not directly convey any aspectual information interact with those that do, thereby influencing the overall interpretation of the state of affairs:

67 It has already been pointed out that in Verkuyl's theory (especially its first version) the compositionality of the aspectual components is applied in terms of V and NP and that the role of adverbials is not properly brought to the forefront. See, in particular, Dowty's (1986) criticism of Verkuyl's approach.

68 An important criticism of his theory of aspectuality (1972) - though rejected by Verkuyl $(1993,17)$ as unjustified - argues that it deals essentially with the logical structures of the syntactic level and excludes the semantic level, see e.g., Dowty (1986), Krifka (1989a) and Sasse (2002). Regardless of the validity of this criticism, however, the following has to be noted: if, on the one hand, Verkuyl rejects any verb classification that seeks to abstract from the context and defends a strictly unidimensional view of aspectuality (i.e., the absence of the distinction of further categories within aspectuality), on the other hand, he deals mainly with morphosyntactic units in the context, because "context" here means rather the syntagma (see also Sasse 2002). While I also choose a unidimensional approach to aspectuality, although based on other criteria, I do not share Verkuyl's view in this regard and favour instead a more semantic aspectological research. 
(13) Fr. Marie-Rose se mit [Pass. Sim.] à chanter.

'Marie-Rose began to sing.'

(14) Fr. Timidement Marie-Rose se mit à chanter.

'Shyly Marie-Rose began to sing.'

The state of affairs illustrated in example (13) clearly shows how different elements play a central role in the overall interpretation of aspectuality:

- Marie-Rose: this is a special kind of noun, a proper name (nomen proprium), which has a high degree of definiteness and various semantic features (e.g., 'living', 'human', 'female').

- chant(-er): if this verb stem is considered as a (lexical) form "in itself" - i.e., regardless of its combination with any inflectional marking (or with the other elements of the verbal periphrasis with which it is associated here) or with its arguments in the utterance - it can be seen as representing a socalled activity, in other words a durative, non-telic, dynamic verb concept, whose initial boundary does not coincide with its final boundary, $t_{x} \neq t_{y}$, and which strives for no natural endpoint.

- se mit à (chant-)er: this is a periphrastic verbal construction consisting of three elements. Two of the elements (se mettre and chanter) are verbal, the other (à) is prepositional; the first verb is inflected (here Passé Simple) and has the function of an auxiliary verb (though not at a very high level of grammaticalisation); ${ }^{69}$ the second has the form of a non-finite full verb. Through this construction, through the combination of these three elements, the temporal (here past), modal (here indicative) and aspectual (here ingressive, punctual and delimited or completed) contents are transmitted cumulatively. It should also be emphasised that the meaning or function of this construction cannot be reduced to the simple sum of the meanings of its three subcomponents, since, for example, neither se mettre nor chanter in themselves have the characteristic of non-durativity independently of the context.

Now the elements of the state of affairs represented in example (14) are the same as those in (13), with a single exception: timidement. And it is precisely the presence of this - on closer inspection modal and not temporal - adverb in (14) which leads to a radically different aspectual interpretation of the state of

69 On grammaticalisation processes and the scalarity of auxiliary verbs, see Heine (1993), on those of verbal periphrases, see Squartini (1998); see also Chapter 6 for verbal periphrases. 
affairs. While - as just stated - the state of affairs in (13) has an internal temporal structuring of the type ingressive, non-durative and delimited, that in (14) is of the type ingressive, durative and delimited. For while the beginning of singing in (13) is something connected with a moment (the very moment of the first note being produced), in the case of a timid beginning to sing in (14) that moment is (based on world knowledge) reinterpreted and in a way stretched out, insofar as all the preparations and attempts to begin singing are contained in this extended period of time. The lexical and grammatical constructions shown in the two examples are related to two different frame structures that represent the contexts, the experiential connections, in which the speaker has learned them and uses them; as such, they are polysemous (see §3.2.4).

An additional example sheds further light on this:

(15) Sp. Leo encontró setas en un bosque de pinos.

'Leo found mushrooms in a pine forest.'

The state of affairs consists in finding several mushrooms by an individual named Leo in a pine forest. The individual components of the state of affairs presented in (15) can be analysed straight away using traditional terminology and it can be seen how the various contents and forms in their mutual interaction participate in its entire tempo-aspectual constitution:

- Leo: this is a special kind of noun, a proper name (nomen proprium), which has a high degree of definiteness and various semantic features (e.g., 'living', 'human', 'male').

- encontr(-ar): if this verb stem is considered in itself (i.e., independently of its combination with any inflectional marking and its arguments in the utterance), here encontrar represents a so-called achievement, in other words a non-durative, telic verb concept whose initial boundary thus coincides with its final boundary $\left(t_{x}=t_{y}\right)$ and which strives for a natural endpoint.

- (encontr-)ó: this is a - cumulative - morphological verbal marking through which temporal (here past), modal (here indicative) and aspectual (here perfective) contents are transmitted.

- seta-s: this is a common noun (nomen appellativum), in particular a plural concrete noun. The use of the plural without the concomitant presence of a particular article shows an absence of definiteness: here we are not dealing with a single or particular mushroom (or several mushrooms that are precisely identified or measured in their quantity), but with any mushrooms 
whose number is unspecified. ${ }^{70}$ It is precisely this absence of determinateness that creates the condition so that the process presented in the state of affairs can be interpreted as reiterated: since no specific mushroom is found and because finding in itself must always be the finding of something in particular, and therefore a striving for a natural endpoint (see above), the state of affairs is reinterpreted as being constituted of several repetitions of the process itself (finding mushrooms).

- en un + bosque (de pinos): this is an adverbial determination (locative) consisting of a preposition (en), an indefinite article (un) and a noun (bosque); the presence of the indefinite article intensifies the absence of definiteness.

Among the various elements, there is apparently an interaction that causes mutual reinforcement, specification, revision, correction and abolition of the wealth of information concerning the temporal internal structure of the state of affairs, and which is regulated by different cognitive mechanisms. This is why it is not always easy to analyse a complex entity, such as a sentence or even a sequence of sentences, in terms of its constitutive parts. The complex unity of a state of affairs, consisting of the combination of two or more components, also possesses semantic autonomy, which arises from this special combination and is linked to its specific context of use. Accordingly, it can only be restrictively analysed when its components are isolated. But that is also why it does not make much sense to speak of verbs (or lexical verb stems) as such, and why I reject a conception of aspectuality based on verb classification and choose instead a frame-based analysis which always considers the components of a situation frame in their relation to the other elements and in their concrete realisation, specific to each case.

We can only hint at an answer to the above-mentioned, legitimate and important question of how the meaning (or meanings) of the subcomponents combine to form the overall interpretation of the state of affairs presented in the sentence, in other words, how these subcomponents are linked together and by which methodological principle this connection is best described and analysed.

One possibility would be to use, as Verkuyl does, the principle of compositionality attributed to Frege, according to which "the meaning of a complex expression [...] [is] a function of the meaning of its parts and its type of syntactic

70 However, it should be noted that here, if the sentence is to be used in a meaningful way in a text it must have a specific indefinite reference, as in un bosque. In other words, the speaker must know that there was this forest and that there were mushrooms that were found by (this specific) Leo. 
connection" (von Stechow 1991, 95, orig. Ger.). ${ }^{71}$ Without doubt, there are many areas of human language in which the principle of compositionality is efficient; or, more precisely, there are certainly structures in a natural language that are compositionally analysable in this sense. However, such a principle can in no way be generalised, as there are several well-known exceptions which cannot be analysed in terms of compositionality, a fact that is well illustrated by, e.g., compounds and phraseologisms (e.g., collocations): ${ }^{72,73}$

(16) Fr. rouge-gorge

'robin'

(17a) Ger. ein starker Mann

'a strong man'

(17b) Ger. eine starke Frau

'a strong woman'

(17c) Ger. ein starker Wein

'a strong wine'

(17d) Ger. ein starkes Argument

'a strong argument'

The meanings of expressions such as in (16) rouge-gorge ('robin') and (17a)(17d) ein starker Mann ('a strong man'), eine starke Frau ('a strong woman'), ein starker Wein ('a strong wine') and ein starkes Argument ('a strong argument') are not simple mathematically-additive compositions of the meanings of their constituents. It is not possible to reconstruct from the sum of the meanings of rouge ('red') and gorge ('throat') that the referent in question here is a bird. ${ }^{74}$

71 The principle of compositionality has been defined in different ways (and also in varying degrees), as in Montague (1974), Wunderlich (1987), etc. For an overview of these and an analysis of the consequences of their differences as well as the general problems arising from the principle of compositionality (also for generative syntax), see von Stechow (1991).

72 Coseriu calls these non-compositionally analysable compounds "exocentric". See Coseriu (1977).

73 The analysis of the following examples in part follows Lee (2001, esp. 73ff.).

74 Let us consider compounds such as Wassermühle ('watermill'), Windmühle ('windmill'), Papiermühle ('paper mill'), Schrotmühle ('grist mill'), Pfeffermühle ('pepper mill'), Sägemühle ('sawmill'), etc.: the word Mühle ('mill') refers to a building or an apparatus in which power (in various forms) is used to drive (various types of) tools in order to obtain a variety of results 
The fact that 'strong' varies semantically from example (17a) to example (17d), and the fact that aspects of encyclopaedic (including cultural) knowledge come into play in interpreting each of these expressions, show that meanings are much better analysed as being the product of a complex interaction between the frames connected to the respective words, and not as a combination of their meanings in a narrower and more traditional sense.

It should now be noted that this access to compositionality cannot only say little about the constructions depicted in (16)-(17a-d), but also about some complex constructions ${ }^{75}$ which contain linguistic realisations of aspectuality, such as those in examples (18)-(20). Another way to address the question of how the elements that linguistically express aspectuality in concrete sentences are linked together would be to adopt an approach based on Construction Grammar.

However, I do not want to adopt a particular model of meaning constitution on the level described above as b), because the perspective chosen in this work and the model arising from it is to be found - let me emphasise this once again - on the other side of the problem, on the level a). In conjunction with the proposal outlined in the next chapters, different approaches are possible, which can build on models based on different theoretical schools of thought, i.e., different semantic assumptions. ${ }^{76}$

(such as producing electricity, pumping water or making a product). This means that different specified semantic linking options are available as targets for the mapping of suitable concepts. In windmill and watermill, the concepts WIND and WATER are classified in the slot TYPE OF POWER SOURCE; in pepper mill and grist mill, the concepts PEPPER and GRIST are arranged in the slot RAW MATERIAL/PRODUCT, and in sawmill, the concept SAW is arranged in the TYPE OF TOOL slot (see Lee 2001). Very interesting here is the extraordinary ability of German to produce compounds: for example, a Windpfeffersägemühle ('wind pepper sawmill') would be a mill that saws pepper with wind power.

75 Constructions in the narrower sense - in the sense of Construction Grammar - are only indirectly dealt with in this book, as the focus and analytical perspective here are onomasiologically oriented. If aspectuality were dealt with from a semasiological perspective, the combination with this approach would certainly be conceivable here. On Construction Grammar in a narrower sense, see among others the works by Fillmore/Kay/O’Connor (1988), Fillmore/Kay (1987), Kay/Fillmore (1999), Croft (2001), Goldberg (1995 and 2006), Tomasello (2003) and, especially on morphology, Booij (2010), as well as, in research on German, Fischer/ Stefanowitsch (2006), Stefanowitsch/Fischer (2008), Lasch/Ziem (2011) and Wildgen (2008).

76 Among the many possible models one could, depending on the theoretical framework, assume, for example, a lexically specified default value that is contextually modified by coercion, or aspectually underspecified predicates which either in principle can assume any aspect value in context or determine the possible aspect values by the frequency of their contexts (this would be the case, e.g., in a use-based approach, etc.). 
But let me present a few more considerations and examples:

(18) Fr. La neige est tombée [Pass. Com.] pendant la nuit. 'Snow fell during the night.'

(19) Fr. La neige est tombée du toit pendant la nuit. 'Snow fell from the roof during the night.'

(20) Fr. La pierre est tombée pendant la nuit.

'The stone fell during the night.'

The verb tomber ('to fall') has a number of specified semantic linking options as targets for the classification of suitable concepts (e.g., in (18) and (19) la neige and in (20) la pierre). However, it is only in the respective frames represented by the examples that the meaning of tomber (and its aspectual configuration) takes on its definitive form. It is only through their world knowledge that the speaker/hearer can express/interpret the aspectual structuring of (18) as that of a reiterative state of affairs: they know that snow (collective) consists of many different flakes, and they assume that when it falls it does not do so all at once but rather the many flakes fall gradually (and then remain on the ground and colour the paths white,...). The aspectual meaning constituted by the interplay of the elements in (18) is thus more than the sum of the meanings of the individual components and the syntactic rule which links them together; and this more results from its emergence in the particular experiential context, from its interaction with world knowledge. Something similar happens in the state of affairs represented by (20). World knowledge enables the speaker/hearer to express/interpret the aspectual structuring of (20) as that of a state of affairs uniquely taking place: they know that the stone is a single object (heavy, subject to gravity, ...) and that, when it falls, unlike in (18), this happens once (then it remains on the ground and ...). It is just this (unique) aspectual meaning that is also expressed by the falling of the snow in example (19), because it can be assumed from the fact that the snow falls from the roof and not from the sky that this is not a series of flakes but rather a compact mass of snow falling all at once (because it has accumulated on the roof first, and we know it will fall all at once). The presence of $d u$ toit, which in itself has no aspectual content, thus considerably influences the aspectual interpretation of the frame on the basis of world knowledge.

Diverse cognitive processes underlie and regulate the combinability of aspectual contents with each other and with other functions of language in the 
scenarios realised in communication. ${ }^{77}$ This combinability makes it possible to attain the most diverse communicative goals, because the possibilities of refinement, modification and correction of aspectual information are almost unlimited: ${ }^{78}$

(21) It. Esplodeva [Imp.] lentamente in mille colori, riempendo il cielo sino a traboccare. L'ultimo fuoco d'artificio svanì [Perf. Sem.] d'improvviso lasciando un bimbo seduto sul suo letto che non s'addormentava [Imp.] per ore. Guardava [Imp.] e riguardava [Imp.] dalla finestra, per ore. Si era fatto quasi giorno e lui guardava [Imp.] dalla finestra. Piano piano il sole sorse [Perf. Sem.], lo salutava [Imp.] sorridente: da due minuti s'era fatto giorno. Leo si alzò [Perf. Sem.] e non si alzò [Perf. Sem.], si girò [Perf. Sem.] e si rigirò [Perf. Sem.] fino a che sua madre strisciò [Perf. Sem.] in un lampo nella stanza portandogli il solito latte col miele.

'It exploded slowly in a thousand colours, filling the sky to overflowing. The last firework faded away suddenly, leaving a boy sitting on his bed unable to sleep for hours. He looked and looked out of the window for hours. It was almost daybreak and he was (still) looking out of the window. Very slowly the sun rose, he greeted it with a smile: day had broken two minutes ago. Leo got up, he didn't get up, he turned over and over again until his mother in a flash crept into the room bringing his usual milk and honey.'

In such a complex text as shown in (21), we can once again clearly see how each additional element influences the overall aspectual content and, in turn, allows for combinations that show its extensibility. Esplodere ('to explode'), which in the traditional classifications of Aktionsart is described as punctual (i.e., non-durative + non-telic), acquires through combination with the durative element, lentamente ('slowly'), aspectual information selected specially for this frame. The reverse behaviour can be seen in the combination of the durative strisciare ('to creep') with the punctual in un lampo ('in a flash', 'in an instance'). The role of the negation in non s'addormentava per ore seems to be particularly interesting (literally 'he did not fall asleep for hours', but here to be understood as 'he was unable to sleep for hours'), because only the presence of the negation allows the transformative addormentarsi (i.e., non-durative + telic) to be combined with a durative element such as per ore ( ${ }^{\star}$ s'addormentava per ore).

77 Here, as will be seen, aspectuality is mainly about contiguity-based processes.

78 In Chapter 4 I show that the combinations are, of course, not completely arbitrary and that there are also combinations which for logical reasons are impossible, i.e., there are restrictions or constraints. 
In summing up again the elements which can express or influence aspectuality on the semantic level of the sentence, ${ }^{79}$ the following need to be mentioned:

- The aspectual information anchored in the verb stem. This represents a particular aspectual configuration (e.g., Fr. être blond vs. rêver) insofar as it contains information about its own combinability with other elements and contents in the frame - of an aspectual or other nature - that can add to the predicate and to the sentence in general. ${ }^{80}$ It interacts with the arguments of the predicate/verb, which in turn can directly constitute an aspectual component, and create a temporal structuring (It. esplosione vs. passeggiata) and links to other nodes of interaction, such as determiners and quantifiers (Sp. comer una manzana vs. comer manzanas vs. comer tres manzanas).

- Further aspectual building blocks are expressed by morphological or morphosyntactic markers (verb stem modifications, derivational or inflectional markers, periphrastic constructions). They also interact with morphosyntactic elements of a non-aspectual nature (for example, with tense or mode markers).

- Adverbials can directly convey aspectual information or evoke it (It. entrò lentamente vs. entrò timidamente).

- Quantification and negation influence the entire aspectual situation frame and not only in conjunction with the arguments (It. non si svegliava per ore

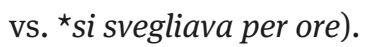

- Finally, word order plays an important role in interpreting the combination of aspectual and non-aspectual elements, cf. It. dall'una alle due pranzo con i miei colleghi vs. pranzo con i miei colleghi dall'una alle due, where in the first case the preferred interpretation is habitual (= dall'una alle due pranzo sempre/normalmente con $i$ miei colleghi), in the second case it is rather a one-off event (= oggi pranzo con i miei colleghi dall'una alle due).

79 It is clear that pragmatic factors can also influence the interpretation of the aspectual situation frame. Combinations of aspectual information that would be logically contradictory may, for example, be interpreted on the basis of inferences or implicatures.

80 The aspectual information interacts with other information of a non-aspectual nature, which is also anchored in the verb stem. See the semantically-founded (but ontologicallyoriented) verb classifications, such as Schumacher's (1986), in which a distinction is made between a) verbs of general existence, b) verbs of special existence, c) verbs of difference, d) verbs of relation and mental action, e) verbs of scope of action, f) verbs of verbal expression and g) verbs of vital needs. But see also the more comprehensive classifications of experience construal, such as, e.g., Halliday/Matthiessen (1999), who distinguish between different domains of experience: "happening and doing” (material), “sensing” (mental), "verbal” (saying), "being and having” (relational). See also Halliday (1985) and Matthiessen (1995). 
Table (1) briefly summarises the above-mentioned elements:

Tab. 1: Formal elements of aspectuality.

\begin{tabular}{|c|c|}
\hline \multirow{6}{*}{$\begin{array}{l}\text { Forms and structures of possible } \\
\text { expressions of aspectual } \\
\text { information }\end{array}$} & verb (stem) \\
\hline & (verb) arguments \\
\hline & morphological marking (inflectional and derivational) \\
\hline & morphosyntactic marking (verbal periphrases) \\
\hline & adverbial determination \\
\hline & $\cdots$ \\
\hline \multirow{7}{*}{$\begin{array}{l}\text { Forms and structures which } \\
\text { interact with aspectual } \\
\text { information }\end{array}$} & (verb) arguments and nodes connected to the arguments \\
\hline & morphological marking (e.g., temporal, modal, ...) \\
\hline & adverbial determination \\
\hline & quantifiers \\
\hline & negation \\
\hline & word order \\
\hline & $\ldots$ \\
\hline
\end{tabular}

\subsection{Summary and a first interim conclusion}

Aspectual information is diverse, structured and combinable. Like all word, sentence and text structures, i.e., every combination of elements resulting in turn from the connection between a form and a meaning, it is based on a principle of productive and selective composition. ${ }^{81}$ This view of aspectuality can be

81 The combination of various aspectual (and other) semantic contents creates patterns that yield either more (through the emergence of new structures or further rules of combinability) or less (through selection) than the sum of the respective parts (see, among others, Fauconnier 1984 and 1999, Goldberg 1995 and 2006, Lakoff 1987 and Langacker 1987, 1990 and 1991). However, with Wildgen (2008) it must also be acknowledged that this conception of compositionality can be problematic: "The operations that Langacker calls construal, Lakoff mapping, Goldberg fusion and Fauconnier blending, have at their core the problem of combining two contents, where the whole is either more (through the emergence of a new structure) or less 
explained particularly well in a frame-based conception of states of affairs - for both the above-mentioned levels (see §3.5) at which we can speak of "aspectual complexity".

On level b) of the realisation of aspectual meaning in a sentence, this meaning is expressed in an utterance in the interplay of various elements that are distributed across all organisational levels of language, from the typically lexical to the typically grammatical. This means that there are a number of specified semantic linking options serving as goals for the classification of suitable concepts with the formal solutions favoured by the respective languages, and that these take on their definitive form only in the respective frame. Co-occurrence of the various elements can mean that the wealth of information pertaining to the temporal structuring of a state of affairs undergoes a mutual process of reinforcement, specification, revision, correction and elimination. On the one hand, the elements that interact in the expression of aspectuality in the sentence can directly serve as an expression of an aspectual (basic) conceptualisation (which does not exclude them also conveying other meaning components, that is, other conceptualisations). But it is also possible that they only influence them and do not convey aspectual information of their own. More specifically, aspectual conceptualisations can be conveyed, for instance, by verb meaning components (cf. It. essere vs. diventare, Fr. partir vs. arriver, Sp. florecer vs. desflorecer), verb arguments (cf. It. la pioggia cade vs. il piatto cade, It. vivere vs. vivere una cosa magnifica, Fr. je mange vs. je mange une pomme), adverbial determination (cf. It. arriva a casa dalle tre in poi vs. arriva a casa vs. arriva a casa alle tre), etc. On the other hand, the elements that only influence them, and that therefore do not convey aspectual information per se, are: adverbials (cf. It. entrò timido/timidamente in classe vs. entrò in classe), negations (cf. It. ${ }^{\star}$ sta lavorando a Roma vs. non sta lavorando (più) a Roma), word order (cf. It. dalle tre alle quattro faccio colazione vs. faccio colazione dalle tre alle quattro), etc.

In discourse, the speaker uses the most varied goals of communication via different communicative strategies (economy, expressiveness, ...) and with the

(through selection) than the sum of the parts. This is also a classic problem in Gestalt psychology. All these concepts may be very specifically realised in individual models, but they all underlie the following problem: given two simultaneously available contents (in perception or in memory), how can they be brought together to create a new meaningful whole that is so stable in its new form that it can also be remembered and communicated. A central problem here is the complexity of the parts and the possible hypercomplexity of the whole, i.e., if the composition exceeds a certain threshold of complexity, the outcome of the composition becomes unstable and thus useless, worthless for thought and communication." (Wildgen 2008, 200, orig. Ger.). 
help of multiple pragmatic mechanisms (implicatures, inferences, ...) to express one or more possible combinations of aspectual information. Each individual language selects its own patterns of delimitation and combination, shows tendencies and preferences, and sets priorities concerning the choice of means by which it expresses the aspectual building blocks and with regards to the levels of organisation on which they are situated in this language. ${ }^{82}$

To approach aspectuality as a complex, universal content category certainly does not mean to deny the diversity of its realisations in the different languages of the world, nor does it mean mixing the means and the procedures it uses or the levels of language on which it is manifested. Rather, it means changing the perspective and trying to insert that diversity into a coherent interpretative framework that insists on its linguistic universality and emphasises its semantic homogeneity. Here, aspectuality is the dimension through which speakers organise a state of affairs according to its particular inherent temporal structure.

The following chapters will present in detail a model for analysing aspectuality and its complex structuring in three perspectives (mentioned above as complexity in the sense of a)), and their possible realisations in the Romance languages.

82 However, some common crosslinguistic patterns can be identified. 